\title{
Surgical ventricular restoration and mitral valve replacement in a pediatric patient with complex congenital heart disease and malignant ventricular arrhythmias
}

Guglielmo Saitto, MD, ${ }^{\mathrm{a}}$ Serenella Castelvecchio, MD, ${ }^{\mathrm{a}}$ Carmelo Arcidiacono, MD, ${ }^{\mathrm{b}}$ and Lorenzo Menicanti, MD, ${ }^{\mathrm{a}}$ San Donato Milanese, Italy

From the ${ }^{\mathrm{a} C a r d i a c}$ Surgery Unit and ${ }^{\mathrm{b}}$ Department of Pediatric Cardiology, IRCCS Policlinico San Donato, San Donato Milanese, Italy.

Disclosures: Authors have nothing to disclose with regard to commercial support.

Received for publication Jan 9, 2019; revisions received April 5, 2019; accepted for publication April 18, 2019; available ahead of print June 14, 2019.

Address for reprints: Guglielmo Saitto, MD, Cardiac Surgery Unit, IRCCS Policlinico San Donato, Via Morandi 30, 20100, San Donato Milanese (MI), Italy (E-mail: guglielmo.saitto@gmail.com).

J Thorac Cardiovasc Surg 2019;158:e189-91

0022-5223/ $\$ 36.00$

Copyright (C) 2019 Published by Elsevier Inc. on behalf of The American Association for Thoracic Surgery https://doi.org/10.1016/j.jtcvs.2019.04.095

- Video clip is available online.

Surgical ventricular restoration (SVR) has been introduced as therapeutic strategy for adverse postinfarction left ventricle (LV) remodeling. ${ }^{1}$ Little information is available regarding SVR in pediatric patients who are rarely affected by coronary artery disease and its related complications.

\section{CASE REPORT}

We report the case of female child with neonatal (2006) diagnosis of aortic coarctation and partial atrioventricular septal defect, including cleft and hypoplasia of the left atrioventricular valve (LAVV) and primum atrial septal defect. After coarctation repair as a neonate, at 3 years of age she underwent partial closure of LAVV cleft and atrial septal defect closure. During separation from cardiopulmonary bypass, a large hematoma of the LV lateral wall was noticed along with ST abnormalities on the electrocardiogram. Transesophageal echocardiogram confirmed the presence of the hematoma and identified inferolateral wall motion abnormalities. Injury to the circumflex coronary artery was suspected, but no revision of the intracardiac repair or attempt to revascularize the myocardium was performed. Postoperative extracorporeal membrane oxygenation support was necessary for approximately 12 hours to obtain a gradual LV recovery; clinical improvement allowed discharge to home on postoperative day 10. Discharge echocardiogram showed mild residual LAVV regurgitation and mild LV ejection fraction (EF) impairment. ST

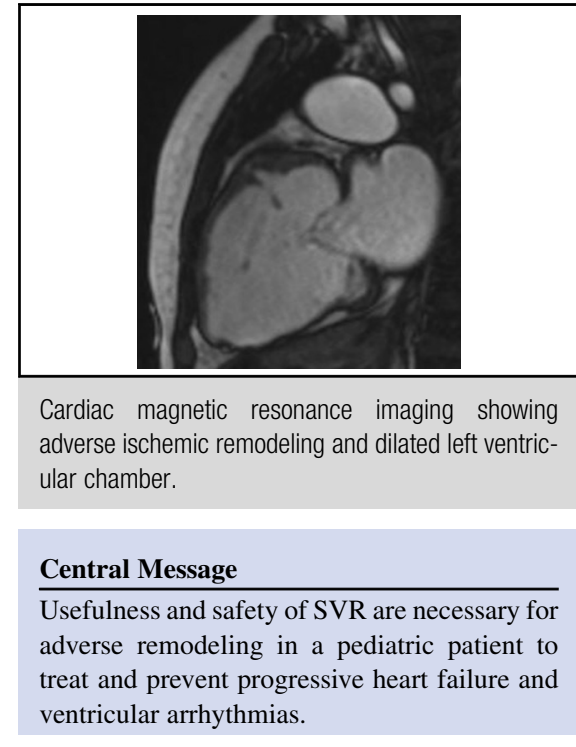

See Commentary on page e193.

abnormalities persisted in the inferolateral and septal leads along with new pathologic Q waves in leads II and V5-6.

The patient was readmitted at 6 years of age for worsening LAVV regurgitation and increasing LV dimensions. Cardiac catheterization showed normal coronary arteries, and the patient underwent surgical closure of the residual LAVV cleft. Predischarge echocardiography showed moderate residual LAVV stenosis and regurgitation in association with moderate LV dilation and dysfunction.

At 9 years of age, the patient was readmitted to the intensive care unit for loss of consciousness due to ventricular tachycardia. After defibrillation and restoration of sinus rhythm, an electrophysiology study was performed: Sequential mapping of LV identified the lower septal and apical regions as the focus for the arrhythmias, but transcatheter ablation was unsuccessful. The arrhythmias resolved with antiarrhythmic therapy (amiodarone and beta-blockers), and the child was discharged after 2 weeks. Shortly thereafter, clinical conditions worsened: Echocardiogram and cardiac magnetic resonance showed severe LAVV regurgitation and moderate stenosis, LV dilation and dysfunction (end-diastolic volume index, $127.2 \mathrm{~mL} /$ 


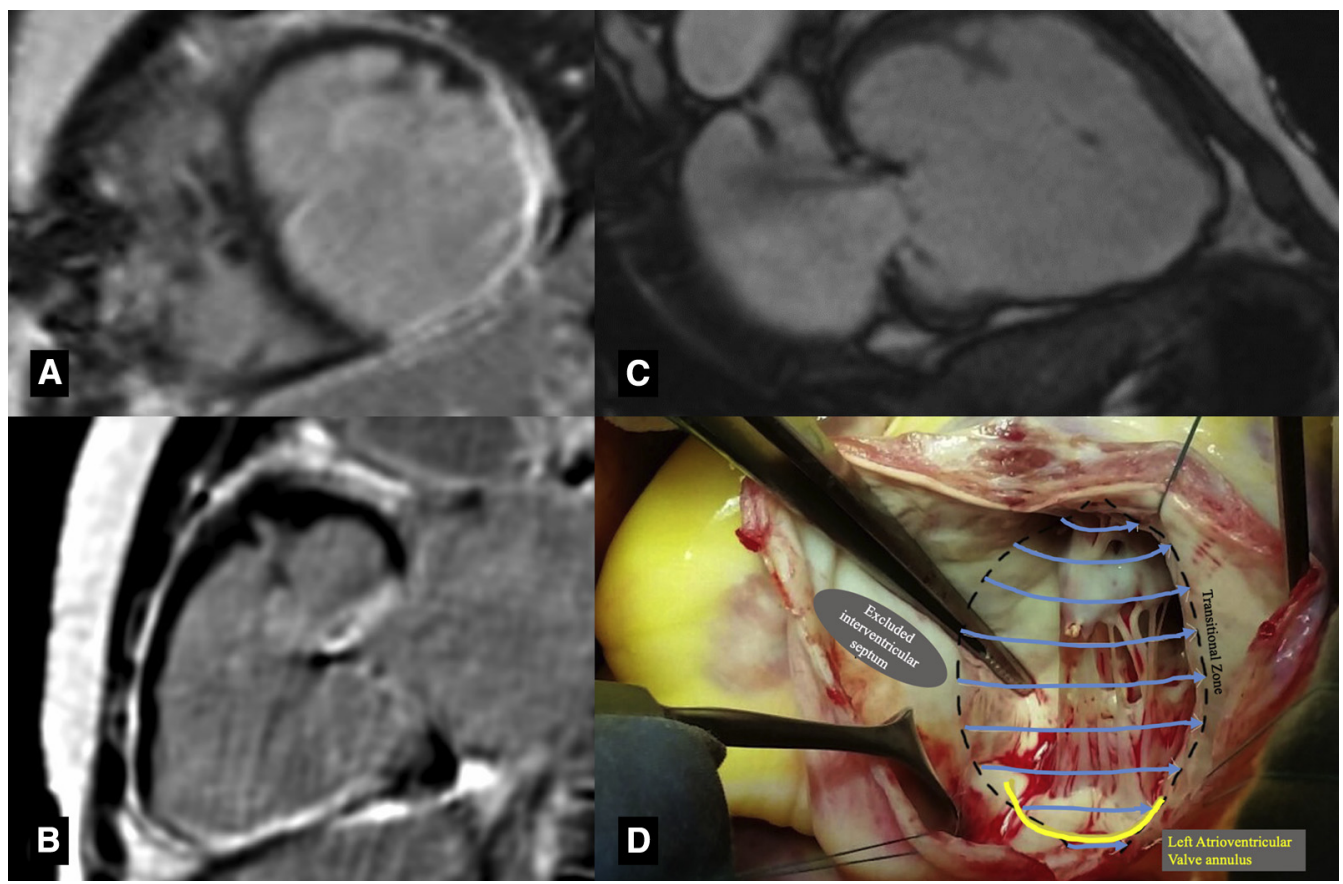

FIGURE 1. Preoperative cardiac magnetic resonance imaging showing an extensive LV posterior scar in late gadolinium enhancement (A, B), and the dilated LV (C) chamber due to an iatrogenic ischemic lesion in the circumflex artery during a previous surgical correction for a partial AVSD, possible ventricular arrhythmia trigger in a 9-year-old patient who underwent posterior SVR. Schematic surgical procedure of the posterior SVR showing the elevated and incised LV from the LAVV annulus (in yellow) to the apex and the "transitional zone" (black dashed line), representing the border between normal and scarred tissue. Blue arrows represent the direct continuous $2 / 0$ Prolene sutures aiming to reapproximate the myocardium beyond the "transitional zone," thus excluding the whole scar (D).

$\mathrm{m}^{2}$ end systolic volume index, $845 \mathrm{~mL} / \mathrm{m}^{2}$, EF $35 \%$ ), and an extensive LV posterior scar, presumed to be a result of evolution of the ischemic injury and exacerbated by the arrhythmias (Figure 1, A-C).

After a discussion with the Heart Team, the patient underwent redo surgery consisting of posterior SVR and LAVV replacement with the mechanical prosthesis Sorin Bicarbon number $23 \mathrm{~mm}$ (Sorin, Saluggia, Italy). The LV was opened at the level of the inferior scarred wall, parallel to posterior descending artery. After digital identification of the border between normal and scarred tissue, termed the "transitional zone," the incision was extended along the entire length of myocardial scar (Figure 1,D). The opening was closed by 2 direct continuous $2 / 0$ Prolene sutures to reapproximate the myocardium beyond the "transitional zone," thus excluding the scar. The excluded tissue was subsequently closed over the first layer to optimize hemostasis (Video 1). The mechanical prosthesis was intra-annularly implanted. Aortic crossclamp and cardiopulmonary bypass times were 93 and 105 minutes, respectively. The postoperative course was complicated by complete aortic valve block requiring the placement of a permanent pacemaker.

The child has been observed over 2 years; the last echocardiography showed a well-functioning prosthesis, with

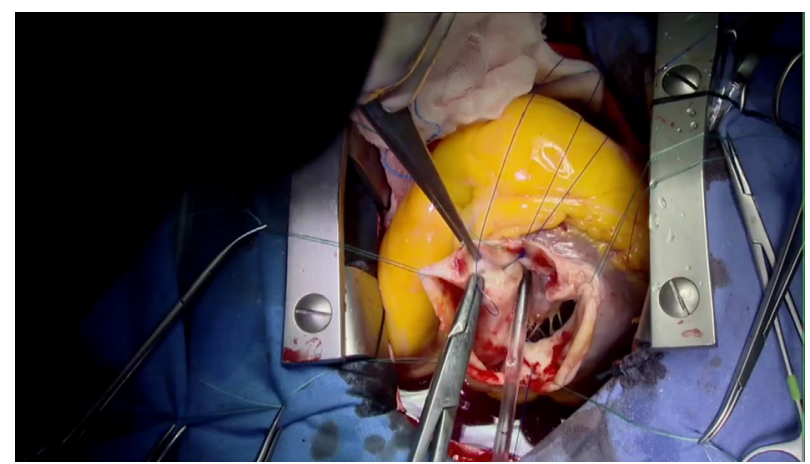

VIDEO 1. The LV is lifted up and opened at the level of the inferior scarred wall, parallel to the posterior descending artery. After initial opening and exposure, a digital exploration and identification of papillary muscles and the "transitional zone," the border between normal and scarred tissues, are performed and the incision is extended along the entire length of myocardial scar. After careful examination of the left ventricular chamber, a first running suture from the annulus of LAVV toward the apex is performed to get the rapprochement of myocardium beyond the "transitional zone" and the exclusion of the scarred tissue. A second suture, started from the distal opening down to the basal segments is conducted, thus excluding whole scar. The remnant-excluded tissue is finally overlapped on the first suture to ensure a better hemostasis. Video available at: https://www. jtcvs.org/article/S0022-5223(19)31034-7/fulltext. 


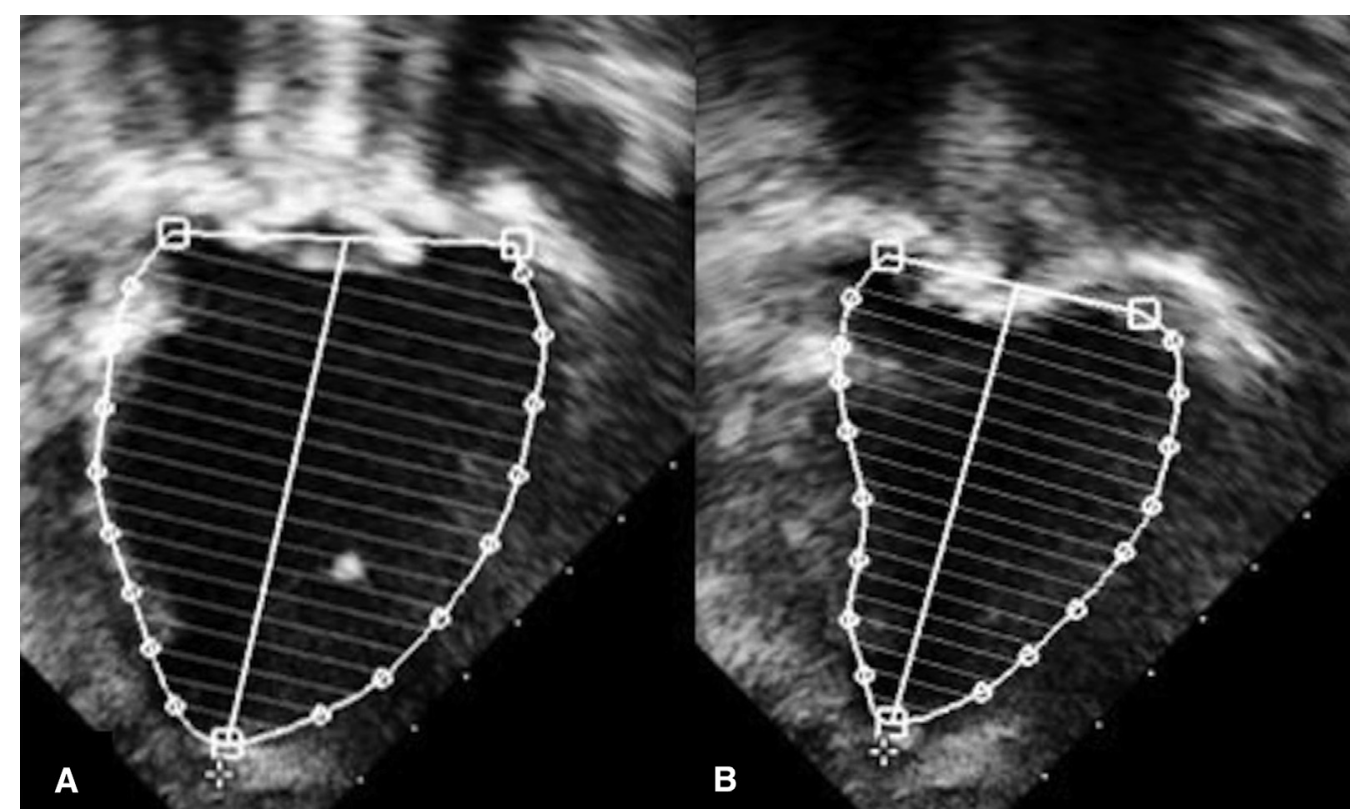

FIGURE 2. Postoperative echocardiogram showing normal function and volumes of the reshaped LV after posterior SVR and LAVV replacement by mechanical prosthesis with exclusion of the scar tissue (A, B).

restored LV contractility and dimensions (end-diastolic volume index $82 \mathrm{~mL} / \mathrm{m}^{2}$, end-systolic volume index $40.6 \mathrm{~mL} /$ $\mathrm{m}^{2}$, EF 50\%) (Figure 2, $A$ and $B$ ). No major arrhythmias or adverse clinical events have been recorded.

\section{DISCUSSION}

To the best of our knowledge, this is the first case of SVR in a pediatric patient who had undergone multiple major surgical procedures. Our 9-year-old patient had a large posterior scar due to LV remodeling and LAVV disease, and presented with dyspnea and malignant ventricular arrhythmias. Our surgical solution aimed to restore LV volume and shape and to exclude the myocardial scar, a potential trigger for electrical instability.

\section{CONCLUSIONS}

In ischemic heart failure, mitral valve repair and SVR have shown controversial results. ${ }^{2,3}$ In our patient, considering her young age, the higher risk of the need for a postoperative permanent pacemaker, and the potential restriction of annular growth, valve repair could have been considered over replacement. A mechanical prosthesis was chosen given the presence of mixed LAVV disease, the history of multiple valve repair attempts, and the need for a definitive surgical solution. The antiarrhythmic benefits of SVR has been demonstrated by several groups ${ }^{4,5}$ and may play an important role in cardiac resynchronization. ${ }^{6,7}$ In our patient, $\mathrm{LV}$ function and volumes improved after SVR and have remained stable during follow-up. The absence of adverse clinical events and arrhythmias speak favorably regarding the feasibility and efficacy of SVR.

\section{References}

1. Di Donato M, Castelvecchio S, Kukulski T, Bussadori C, Giacomazzi F, Frigiola A, et al. Surgical ventricular restoration: left ventricular shape influence on cardiac function, clinical status, and survival. Ann Thorac Surg. 2009;87: 455-61.

2. Castelvecchio S, Parolari A, Garatti A, Gagliardotto P, Mossuto E, Canziani A, et al. Surgical ventricular restoration plus mitral valve repair in patients with ischaemic heart failure: risk factors for early and mid-term outcomes. Eur J Cardiothorac Surg. 2016;49:72-8

3. Kron IL, Hung J, Overbey JR, Bouchard D, Gelijns AC, Moskowitz AJ, et al. Predicting recurrent mitral regurgitation after mitral valve repair for severe ischemic mitral regurgitation. J Thorac Cardiovasc Surg. 2015;149:752-61.

4. Sartipy U, Albåge A, Strååt E, Insulander P, Lindblom D. Surgery for ventricular tachycardia in patients undergoing left ventricular reconstruction by the Dor procedure. Ann Thorac Surg. 2006;81:65-71.

5. Mikleborough LL, Merchant N, Ivanov J, Rao V, Carson S. Left ventricular reconstruction: early and late results. J Thorac Cardiovasc Surg. 2004;128: 27-37.

6. Di Donato M, Toso A, Dor V, Sabatier M, Barletta G, Menicanti L, et al. Surgical ventricular restoration improves mechanical intraventricular dyssynchrony in ischemic cardiomyopathy. Circulation. 2004;109:2536-43.

7. Breithardt OA, Stellbrink C, Herbots L, Claus P, Sinha AM, Bijnens B, et al. Cardiac resynchronization therapy can reverse abnormal myocardial strain distribution in patients with heart failure and left bundle branch block. J Am Coll Cardiol. 2003;42:486-94. 